\title{
Estudos
}

\section{Educação Indígena e Bilingüismo: o Caso do Acre}

\section{Nietta Lindenberg Monte}

Faculdade Latino-Americana de Ciências Sociais (FLACSO)

Analisa algumas variáveis sociolingüísticas relativas à utilização e ao ensino das línguas indígenas e portuguesa, para além da atitude e da consciência lingüística dos índios professores que as ensinam e de seus alunos e parentes envolvidos no projeto de educação coordenado pela equipe desta pesquisa. A vivência social de um bilingüismo equilibrado tem sido a meta da maioria dos projetos ligados ao futuro dos índios. Para tal, vem sendo enfatizada a necessidade de elaboração de currículos bilíngües para as escolas indígenas brasileiras, a exemplo do que ocorre em outros países do continente. Essa necessidade se coloca em regime de urgência, visto estarmos longe de um bilingüismo harmônico; ao contrário, temos assistido à coexistência conflituosa e assimétrica das línguas indígenas com a língua nacional, com fortes indícios históricos de progressiva expansão do português e retração ou desaparecimento das línguas indígenas.

\section{Introdução: relato da trajetória}

O texto é uma versão preliminar de uma pesquisa iniciada em janeiro de 1989, sob o nome de Repensando a Educação Bilíngüe e Intercultural: o caso do Acre, ligada à Faculdade Latino-Americana de Ciências Sociais (FLACSO), com recursos provenientes do Instituto Nacional de Estudos e Pesquisas Educacionais (INEP). Teve como objetivo realizar uma descrição, seguida de análise e avaliação, da utilização e do estudo das 
línguas indígenas e do português nas comunidades indígenas do Acre, especificamente daquelas onde se desenvolvem as escolas bilíngües do Projeto Uma Experiência de Autoria, da Comissão Pró-índio do Acre (CPI/AC). ${ }^{1}$

Optou-se pelo uso de práticas de investigação, com os seguintes instrumentos: questionários semifechados de cunho sociolingüístico, desenhados para obter as preferências quanto à distribuição do uso das línguas em diferentes situações comunicativas, mediante enunciados superficiais da reflexividade metalingüística dos falantes índios, que são atualmente os atores diretos e indiretos do Projeto de Educação Indígena da CPI/AC. São eles: os professores bilíngües; os alunos das escolas e seus pais, avós e parentes em geral; membros de diferentes faixas etárias, sexo, posição social e nível de escolaridade das comunidades indígenas.

$\mathrm{O}$ instrumento foi a observação participante, através de viagens às aldeias, para assessoria pedagógica aos professores e alunos. Nas escolas, eram realizadas "oficinas", com atividades didáticas ligadas à pesquisa das línguas indígenas, sua descrição e registro feitos pelos próprios professores bilíngües em forma de cartilhas escritas, durante os cursos de formação sob nossa coordenação. No período da pesquisa, dois cursos dedicados à língua Kaxinawá deram como resultado a primeira cartilha nessa língua, de autoria de professores bilíngües. Visitas diversas às aldeias Shanenawa e Jaminawa, grupos da família lingüística Pano, também resultaram na elaboração de duas cartilhas pelos professores dessas etnias. Os três materiais já foram publicados pela CPI/AC, com a finalidade de dar corpo e apoio aos processos de alfabetização em línguas maternas ou na segunda língua dos alunos daquelas escolas. ${ }^{2}$

\footnotetext{
${ }^{1}$ Este projeto envolve a formação de recursos humanos indígenas para o magistério de $1^{\circ}$ grau, tendo assessorado a implantação de 37 escolas indígenas no Acre e no sul do Amazonas. Desde 1983, a responsável pela pesquisa faz a coordenação geral deste projeto e a assessoria em língua portuguesa. Mais informações, consultar na bibliografia MONTE, Nietta - 87, 88, 89 .

${ }_{2}$ Para apoiar este aspecto da intervenção pedagógica, passamos a contar desde outubro de 1989 com a colaboração cientifica da lingüista Adair Palácio e de uma equipe de alunos e orientandos da Universidade Federal de Recife, que vêm se dedicando, com o apoio do CNPq, á descrição de quatro dessas línguas, especialmente selecionadas devido ao escasso número de falantes que apresentam; por exemplo, as línguas Poyanawa e Arara, cujos falantes não totalizam mais de 10 indivíduos com mais de 40 anos. Ou aquelas como as faladas pelos Shanenawas e parte dos Kaxinawás, em que a socialização das crianças é feita sobretudo em língua portuguesa, sendo a língua indígena sua segunda língua (conhecimento passivo desta língua: entendem, mas não falam).
} 
A aplicação dos questionários aos alunos, professores e membros da comunidade, nas áreas com escolas, com caráter de amostragem, foi realizada com a ajuda de diferentes atores: alguns professores bilíngües, assessores pedagógicos e consultores ligados ao projeto da CPI/AC, durante suas visitas às aldeias. ${ }^{3}$ A situação comunicativa criada pelos questionários, nos quais algumas perguntas solicitavam dos falantes a elaboração verbal de enunciados metalingüísticos argumentativos, deulhes a oportunidade de promover a reflexividade, ainda que superficial, sobre as condições de conflito lingüístico e intercultural vividas por eles. Enquanto intervenção pedagógica, o uso do questionário criou a oportunidade de trazer à consciência desses falantes as contradições por eles vividas, ao terem que lidar com escolhas diárias entre as línguas, tanto no nível da distribuição dos usos, nas variadas situações de comunicação, quanto no nível de suas atitudes e representações metalingüísticas.

Neste sentido é que nossa pesquisa encontra seu caráter pedagógico: destina-se à formação de uma consciência progressiva nesses falantes sobre suas línguas maternas, ou as línguas de seu grupo étnico, em relação ao português, tentando tomar-lhes cada vez mais conscientes da tendência principal que temos constatado dentro do próprio Projeto, de valorização assimétrica do ensino-aprendizagem do português oral e escrito nas escolas e mesmo fora delas. Se, de início, apoiamos tal tendência, promovendo cursos de formação de professores bilíngües, das diversas disciplinas do currículo, com ênfase no estudo da Língua Portuguesa, e em língua portuguesa, com produção de muitos materiais didáticos de autoria indígena, atendendo à principal reivindicação dos falantes índios envolvidos no projeto, hoje, avaliamos ser necessário repensar essa tendência em conjunto com os atores diretos e indiretos nas escolas. Daí estarmos desenvolvendo esta pesquisa, cujo caráter de produção científica e intervenção pedagógica apenas aqui se esboça e inicia.

\footnotetext{
${ }^{3}$ Equipe de auxiliares da pesquisa: Vera O. Sena, M. Djacira Maia, M. Francisca Chagas, Renato Gavazzi e os professores indígenas bilíngües dos grupos: Kaxinawá.Apurinã.Katukina, Jaminawa.Poyanawa.Shawanawa, Shanenawa, Manchineri.
} 


\section{Definição do campo}

Lidamos, como mola mestra de nossa pesquisa, com o conceito de diglossia, retomado por sociolingüistas como R. Enrique Hamel; Hector Munoz; M. Tereza Sierra, que reconceituaram modernamente a diglossia, entendendo-a como relação dialética, assimétrica e não-estável, de duas tendências: uma, a principal, de expansão geográfica e funcional das línguas dominantes e de concomitante retração das línguas dominadas. A outra tendência, subordinada, é a de recuperação, resistência e manutenção dessas línguas, que, muitas vezes, séculos de colonização não conseguiram fazer desaparecer.

A tendência principal revelou-se ao longo do processo histórico de colonização, seguida de geno e etnocídio das populações indígenas em muitos países do continente americano. Seu fio condutor é, do ponto de vista lingüístico, a passagem de um monolingüismo em língua materna indígena, seguida de um bilingüismo funcional crescente, característico da etapa atual em nosso caso acreano, podendo-se chegar, se a tendência principal continuar, a um monolingüismo na língua majoritária e oficial, com o desaparecimento completo dessas línguas indígenas.

No caso por nós estudado, ao olharmos o contexto macrossocial onde ocorre o conflito, fatores sócio-econômicos reforçam a tendência principal: o envolvimento dos índios seringueiros na economia de mercado, a modernização do extrativismo através dos novos sistemas de "cantinas e cooperativas indígenas", dos financiamentos conseguidos para essa finalidade mediante projetos econômicos ou de "desenvolvimento comunitário", normalmente apoiados pelas Organizações NãoGovernamentais (ONGs) da região, ${ }^{4}$ com recursos nacionais e internacionais de agências ambientalistas e humanitárias localizadas no Primeiro Mundo.

\footnotetext{
${ }^{4}$ Organizações Não-Governamentais (ONGs) locais: Comissão Pró-índio, Conselho Nacional de Seringueiros, União das Nações Indígenas e Centro de Trabalhadores da Amazônia.
} 
Existem também fatores ideológicos como políticas locais e nacionais de escolarização em língua portuguesa, com a reprodução dos programas da escola brasileira rural inteiramente em português e de português. Tais políticas, não-explícitas, fragmentadas em várias ações educativas para indígenas, vêm sendo executadas por agentes diversos na região do Acre e em todo o Brasil e, embora expressando metas, às vezes, distintas, têm conduzido a um resultado único — o reforço da tendência principal.

A tendência subordinada se manifesta como capacidade de recuperação e resistência das línguas indígenas, apoiadas por fatores sócio-econômicos como a falência de um modelo capitalista predatório, que se revela no baixo nível de vida das populações urbanas e rurais, na violência no campo e nas cidades e na degradação moral e ambiental. No seu aspecto ideológico, manifesta-se a construção de um novo projeto de sociedade e meio ambiente onde passam a ter vez e lugar "as diferenças". No Brasil, no final da década de 80, a vida e a morte de Chico Mendes, a organização da "Aliança dos Povos da Floresta", unindo índios, seringueiros etc, formam os alicerces de um novo modelo de "humanidade" não apenas regional, onde a defesa do planeta Terra, dos índios e das populações da mata, expressas em diversas línguas, ocupam lugar fundamental.

Assim, o projeto de educação indígena coordenado por nós desde 1983 é reflexo mesmo dessas duas tendências. Se, por um lado, expressa e reforça a valorização assimétrica da língua portuguesa - estando centrada nesta língua a meta e, em muitos casos, o veículo da escolaridade de adultos e crianças —, por outro, a escola é também parte da reconstrução atual por que passam as sociedades indígenas, quando tomam conhecimento de seus direitos a uma chamada "cidadania diferenciada", portanto, à manutenção de uma identidade diferencial e étnica, autoidentificadora do grupo e dos indivíduos indígenas.

Movimentos reivindicatórios e ações de mudança vêm ocorrendo no Acre desde 1980, com a reapropriação territorial e o reavivamento de aspectos das culturas indígenas como artesanato, rituais, processos de denominação (nomes próprios) e também a revitalização das próprias línguas. No campo sócio-econômico, as relações de produção saíram da 
rede de exploração do seringal tradicional e passaram a ser tecidas sob as ordens de uma liderança indígena (Tuxawa, cacique), com o apoio das entidades de assessoria locais. As escolas de $1^{\circ}$ grau, reivindicadas unanimemente pelas sociedades indígenas, nesta fase, saem da direção e orientação de "professores brancos", representantes dos principais agentes de contato: patrão seringalista, Funai e missões religiosas fundamentalistas, católicas e protestantes, para serem geridas pelo professor bilíngüe, com o apoio financeiro e técnico das entidades e dos órgãos do poder público. Constrói-se, coletivamente, o projeto pedagógico, em reflexões durante assembléias indígenas e cursos de formação, tais como esta:

O que queremos aprender daqui para frente é isso, som "a" e "an". Pontuação, til, vogais. Quais são as diferenças do s, ç, já, xa, cha, ga, gue, gui. E do que, qui e do ca, co cu. Mas isto é de vocês. Nós sabemos o som dessas letras: y, $\mathrm{w}, \mathrm{k}$ e a letra [-]: [-]: [-]: [-]: [-] (Siã Kaxinawá in Escolas da Floresta, Comissão Pró-Índio do Acre, 1980).

... O que queremos aprender é a linguagem portuguesa para fazer um contrato com a SUDHEVEA ${ }^{5}$, aprender botar dinheiro no banco... a pontuação, a significação das palavras para entender a cultura do Brasil... e a nossa língua para não esquecermos dela, as estórias de antigamente, a dança do Mariri, a cantiga cipó, o artesanato..." (Kiã Kaxi. Ibidem).

A meta é um bilingüismo difuso, já que não detalha e planifica que função e papel desempenharão cada uma das línguas na formulação do currículo escolar.

A discussão sobre bilingüismo entre os índios diretamente ligados ao projeto e em nossa própria equipe esteve, pois, mais no campo da reflexão étnico-política, da tomada de consciência dos direitos indígenas gerais como terra, saúde, desenvolvimento sócio-econômico, acesso a serviços públicos diversos, sem perder de vista o direito às diferenças, entre estas, as próprias línguas.

\footnotetext{
${ }^{5}$ Sudhevea: órgão federal já extinto, encarregado do fomento e da regulação do extrativismo da borracha.
} 
Faltou, porém, a essa discussão, instrumental mais técnico, nos campos lingüísticos e pedagógicos, como oque pretendemos estar iniciando nesta pesquisa: ao descrever as condições sociolingüísticas atuais do conjunto de alunos, professores e comunidade, visamos a mapear as diversidades e homogeneidades da situação de bilingüismo nas diferentes aldeias da região. A finalidade pedagógica maior é poder vir a planejar, a médio prazo, em conjunto com os atores indígenas, os possíveis caminhos a serem seguidos para a confecção e execução de um currículo bilíngüe e intercultural, já almejado e vislumbrado nas metas políticas por eles formuladas.

Se nesta fase da pesquisa, de redação do relatório final, o trabalho é solitário, de sistematização escrita dos dados empíricos recolhidos pela equipe entre os falantes bilíngües índios, numa outra etapa, a ser brevemente iniciada, pretendemos trabalhar pedagogicamente com eles o retorno da análise, com vistas a sua progressiva conscientização sobre as suas reais condições sociolingüísticas vividas (nem sempre conscientemente por eles), e a formulação participativa de um currículo indígena de $1^{\circ}$ grau, com desenho bilíngüe e intercultural, para que sua execução a médio e a longo prazos possa ser realizada com consciência nova por esses sujeitos.

Para finalizar esta introdução, cito Luís Antônio Cunha, autor que no campo educativo brasileiro indica caminhos para a construção de uma nova prática pedagógica:

Toda pedagogia diz que a prática dos educadores está voltada para a transformação das circunstâncias e esta é feita pela transformação dos homens... É dos educadores que nasce a formulação das pedagogias, mas sua finalidade é a transformação das circunstâncias. Mas como articular as intenções dos educadores com as circunstâncias onde essas intenções atuam e para as quais estão destinadas? (in: Quem Educa os Educadores. Educação e Sociedade, São Paulo: CEDES, 1980).

Como educadores de educadores indígenas bilíngües, e pesquisadores a serviço dessa prática pedagógica, nossa tarefa é a elucidação das 
circunstâncias, especificamente as condições sociolingüísticas, como parte de um macronível sociopolítico. Será a partir da reflexão sobre as circunstâncias que se poderá trazer à consciência desses educadores o caráter contraditório da realidade por eles vivida e da sua própria consciência sobre essa realidade. Assim,

... não seria mais rica uma pedagogia que levasse a sério o fenômeno da consciência contraditória? (...) a contradição interna entre uma consciência que sabe e outra que nega esse saber? (...) Isto é, a divisão interna entre a clara e total consciência de uma dada situação e, diante do sentimento ou da percepção da impossibilidade de transformá-la, surge uma segunda consciência, um segundo discurso, uma segunda prática, que negam ou anulam aquilo que realmente sabem? Levar em conta esse fenômeno não seria enfrentar cara a cara o enigma da dominação?... (CHAUI, Marilena, Ideologia e Educação. Educação e Sociedade, n.5, CEDES-SP/80).

A pesquisa: preferências e argumentos metalingüísticos

Parte dos resultados da pesquisa tratou de registro, classificação e análise das preferências por língua portuguesa (LP) e por língua indígena (LI), explicitadas pelos 110 falantes entrevistados, ao responderem 15 perguntas sobre o conflito lingüístico vivido. Tratou-se, também, da classificação e análise dos argumentos formulados pelos entrevistados, ao justificarem suas preferências por LP e por LI.

Organizamos dois eixos lógicos nos quais as respostas se alojavam: eixo simétrico A e B e eixo assimétrico A ou B. No eixo simétrico estão as respostas a favor do bilingüismo, LP e LI. No assimétrico, as respostas a favor da LP, com exclusão da LI, ou a favor da LI, com exclusão da LP.

Elaborou-se uma tipologia para dar conta da variedade de respostas, classificadas em 14 enunciados metalingüísticos, e estes foram enquadrados em quatro tópicos relativos à concepção de língua e conflito lingüístico.

Tentou-se relacionar as idéias gerais da representação dos falantes 
sobre os processos de aquisição e desenvolvimento das línguas indígenas e do português e sobre o conflito lingüístico por eles experimentado cotidianamente, numa perspectiva que abrangesse as outras dimensões da vida social, cultural e política, entendido o lingüístico como parte dos conflitos interculturais.

$\mathrm{Na}$ análise das respostas, verificando qual dos eixos determinou maior número de enunciados, vimos que o eixo pró-bilingüismo e pró-português recebeu maior número de respostas no conjunto das perguntas. Ao analisarmos o tipo de perguntas em que os falantes deram preferência à língua portuguesa, vimos que estas diferem das perguntas em que os falantes deram preferência ao bilingüismo: para a LP convergiram preferências quando o assunto era a "língua de preferência para ler e escrever", a "língua de maior utilidade para a escrita e a leitura" e para a "alfabetização de adultos". As perguntas cujas respostas os falantes deram preferência à LP e à LI (ou pró-bilingüismo) foram as que solicitavam "língua melhor para o índio falar e estudar na escola", "a mais bonita", e "a preferida para a aquisição oral e escrita das crianças". Nessas perguntas, fica realçado o aspecto da identificação afetiva, através da adesão estética e cultural, onde os enunciados expressam a qualificação étnica e as práticas de interação verbal escrita dentro e fora do grupo étnico.

Como vimos, a natureza diversa do conteúdo das perguntas orientam a variação das tendências: as que reuniram maiores preferências próbilingüismo estão ligadas a um projeto de indianidade, no campo das expectativas e do desejo, com forte carga afetiva e étnica. Bilingüismo neste caso não significa a constatação histórica de uso simétrico e equilibrado das duas línguas pelos falantes, mas um projeto de futuro a ser conquistado. As perguntas cujas respostas foram majoritariamente próLP referem-se ao cotidiano da história da lecto-escritura e realçam a funcionalidade social da LP e o seu enorme prestígio para as atividades de escolarização. 
TIPOLOGIA DOS CONTEÚDOS METALINGÜÍSTICOS DOS ENUNCIADOS SOBRE A CONSCIÊNCIA DOS FALANTES

A tipologia abaixo resulta de uma classificação elaborada quando relíamos os dados empíricos registrados em forma de curtos enunciados, a fim de encontrarmos as regularidades de certos modos de pensar o lingüístico e a aprendizagem por parte dos falantes índios entrevistados. Depois de estes relacionarem, na primeira parte dos questionários, sua(s) língua(s) de preferência segundo as diversas situações comunicativas, seguia a pergunta: "Por quê?", cujas respostas em forma de argumentos simples puderam ser classificadas assim:

a) Eficácia e extensão do ato comunicativo

b) Ruído e preservação do ato comunicativo

c) Facilidade e naturalidade para a aquisição lingüística

d) Valor e significado étnico do lingüístico

e) Perspectivas, resistência e substituição lingüística

f) Perspectivas econômica, social e política da competência lingüística

g) Perspectiva intelectual da competência lingüística

h) Determinantes não-específicos da aquisição e da competência lingüística

i) Motivação afetiva da aquisição e da competência lingüística

j) Sem explicação

k) Fatores para a aquisição e a manutenção lingüística via educação informal

1) Fatores para a aquisição e manutenção lingüística via educação formal

m) Casamento interétnico e competência

n) Migração e competência.

ENQUADRAMENTO DA TIPOLOGIA

Enquadrando essa tipologia em quatro tópicos gerais que se referem 
ao lingüístico, chegamos ao seguinte resultado:

1. Aspectos comunicativos e funcionais da competência lingüística: a, b

2. Fatores condicionantes da aquisição e da competência lingüística: c, h, i, k, 1, m, n

3. Valor e perspectivas da resistência linguística: d, e

4. Objetivos e perspectivas da aquisição e da competência lingüística: $\mathrm{f}, \mathrm{g}$

\section{EXPLICAÇÃO DA TIPOLOGIA DOS ENUNCIADOS REFERENTES}

À CONSCIÊNCIA LINGÜÍSTICA

Estabeleçamos como "categorias" os itens alfabéticos correspondentes utilizados na tipologia dos conteúdos metalingüísticos:

a) Compreendemos nesta categoria os enunciados que realçam o caráter comunicativo da(s) língua(s) no sentido de ato social que envolve o emissor e o destinatário, e onde se dá a interação através da transmissão verbal (oral e escrita) de mensagens. Nos enunciados assim reunidos, a eficácia da comunicação lingüística entre emissor e destinatário, através da competência em LP e em LI, se resolve mediante qualificações positivas dos atos comunicativos de "falar", "entender", "dizer mais fácil", "sem embaraço", "melhor", como por exemplo: "nós entende mais fácil"; "é mais fácil de falar"; "sabemos dizer melhor"; "não tem muito embaraço".

Assim, garante-se a extensão da comunicação a um maior número de destinatários: "posso encontrar meus parentes, e os brancos também falam"; "para conversar com todo mundo..."

b) Sob esta categoria estão reunidos enunciados que, embora também realcem o caráter comunicativo da língua, o fazem ao inverso de A: a função neste caso é não comunicar, provocar ruído, fazer desentender a mensagem pelo uso de um código desconhecido do destinatário "indesejado" pelo emissor; a mensagem destinar-se-ia apenas aos que 
partilham do mesmo código do emissor - seu grupo étnico. Exemplos: "a língua indígena os brancos não entendem, nós falamos o que quiser na frente dos brancos"; "a nossa, porque ninguém compreende".

c) Reunimos nesta categoria enunciados cujos conteúdos apontam para fatores sociolingüísticos condicionantes da aquisição e da competência em LP e em LI: ser a língua materna é um deles: "nasci com ela"; "aprendi logo". Estar exposto a ela é outro fator realçado: "os amigos conversando... a gente feito papagaio velho aprende"; fui criado no meio dos brancos". Ou seja, a aquisição e a competência oral e escrita em uma das línguas ou em ambas é explicada pela facilidade e a naturalidade do processo de aprendizagem, sendo a língua para a qual está exposto de uso e costume do meio social onde vive o falante: "é mais fácil para aprender a ler e escrever"; "sou acostumado já".

d) Agrupamos nesta categoria os conteúdos dos enunciados que qualificam o lingüístico com valores extralingüísticos, como o significado étnico, histórico, da competência em uma determinada língua: "a nossa língua é nossa cultura, história, tronco, herança, tradição". A língua aqui é veículo condutor e definidor do conceito de identidade: "é uma honra saber a nossa língua"; "é a língua do índio legítimo...". Identidade étnica, que se define na valorização do uso de uma língua "própria", "nossa", que identifica e diferencia um "nós" (índio) em relação a um "outro" (branco): "a coruja tem de valorizar o seu toco... valorizar o que é meu antes de valorizar o que é dos outros".

e) O valor étnico da língua, perceptível na categoria $D$, recebe na categoria E tratamento diacrônico, retirando-lhe da posição relativamente estável que tinha em D e atribuindo-lhe sua condição histórica, portanto, possível de sofrer modificações e deslocamentos no conflito lingüístico com o português. Verbos e locuções como "esquecer", "perder", "deixar de falar" expressam a consciência diglóssica da perspectiva de substituição lingüística e ao mesmo tempo a expectativa de resistência étnica diante da língua e da cultura portuguesa, majoritárias e "predominantes": "se a gente aprender só o português, a língua portuguesa predomina na língua indígena e aí acaba com nossa cultura..."; "porque índio não pode perder a língua". 
f) Nesta categoria englobamos as perspectivas econômica, social e política da aquisição/competência lingüística. Através do domínio da língua se objetivam mudanças individuais e/ou sociais para os falantes, segundo a natureza de seus interesses: 1) econômica: "negócios", "compra e venda", "cooperativa", são termos e novas práticas de contato pelas quais os falantes se inserem nos mercados regional e nacional, utilizandose exclusivamente da língua portuguesa, do que resulta mais "desenvolvimento" e "progresso" pessoais: "falando bem a gente faz negócio bem"; "é a língua desenvolvida"; "lidar no comércio, na cantina"; "mais fácil não ser enganado pelo patrão"; 2) social: visa-se pelo domínio lingüístico a uma melhor organização social e a conhecimentos que capacitariam o grupo para melhor administrar a si mesmos dentro da nova ordem: "saber administrar nossa própria cultura"; "fazer reunião, organizar"; 3) política: visa-se, também, através do lingüístico, ao estabelecimento de novas relações com o todo, o geral, "o nacional", mediante a capacidade de reivindicar e negociar com este destinatário novo, o "Governo Brasileiro", os itens que lhes interessam para a construção de sua identidade em novas bases: "tem que negociar com os brancos"; "estamos envolvidos na sociedade"; "português é mais usado em termos de nacionalização"; "saber reivindicar, fazer documento para Governo Brasileiro, nós que vivemos num país chamado Brasil".

g) Estão reunidos nesta categoria enunciados que apontam para as perspectivas intelectuais de maior conhecimento e informação abertas pela aquisição linguiística: "aprender mais", "conhecer coisas que a gente não sabe", adquirir conteúdos de conhecimentos gerais (de caráter lingüístico e cultural) não especificados nas argumentações pró-LP "aprender falar bem"; "conhecer a cultura do branco"; "aprender a falar mesmo as palavras do branco" - e pró-LI: "para informar, construir de novo a história antiga"; "a língua dos antigos (pura mesmo) a gente não sabe".

h) Aqui se agrupam os enunciados que expressam as determinantes gerais da aquisição e da competência lingüística, com forte carga normativa de obrigatoriedade e necessidade não explicadas: "tem de aprender"; "a 
gente precisa"; "deve falar as duas"; "na aldeia é necessário, na cidade temos que aprender".

i) Enfoca-se aqui predominantemente o caráter de motivação e intencionalidade afetiva como determinante da aquisição, da competência e da preferência lingüística. A adesão do sujeito está explícita nesta categoria mediante verbos como "gostar", "querer", "ter vontade", ao contrário dos verbos da categoria anterior, que indicam uma ação exterior, involuntária, sobre o indivíduo em expressões como "tem de", "deve de": "gostaria muito de poder falar"; "a vontade de ter aprendido me faz ver boniteza nela"; "quero aprender a lei do branco".

j) Nesta categoria englobamos os enunciados considerados "sem explicação", que sofrem variações desde respostas como "não sei", nenhuma resposta (com a recusa ou abstenção em explicar-se), até respostas cujos enunciados nada argumentam, do tipo "eu acho mesmo", ou que repetem a própria pergunta: "porque é bonita mesmo".

k) Reunimos sob esta categoria os enunciados que realçam o papel dos circuitos de transmissão informais de natureza oral, de caráter tradicional e educativo, como condicionantes estratégicos da aquisição e da competência lingüística. Falar a língua entre os membros da família, em conversas e "reuniões" de pai para filho, de velhos com novos, são os mecanismos realçados na argumentação sobre o conflito lingüístico a favor da resistência da LI: "caso encontramos com velho, temos de falar na língua"; "o jeito que tem é ensinar aos que estão nascendo"; "pessoal se reunir, ajuda a língua".

1) Aqui agruparam-se os enunciados que em sua argumentação atribuem à educação formal, ao professor bilíngüe, às capacidades de ler e escrever, resumidas no objeto "cartilha", as perspectivas estratégicas para a aquisição e a competência lingüística oral e escrita: "a escola pode ajudar a língua ensinando a falar, ler, escrever"; "se viesse um livro para ensinar"; "se o professo- ensinar direito"; "para, se tiver o massacre, nós termos como nos defender pelas cartilhas"; "escreve lamparina no português e faz na língua. Quem não sabe vai aprendendo".

m) Enquadraram-se aqui enunciados que qualificam o casamento 
interétnico como fator extralingüístico determinante para a aquisição de competência lingüística em LP: "já tá tudo misturado"; "casei com branco e mamãe tinha vergonha de ensinar nós".

n) Aqui os argumentos qualificam a migração (migração dos índios para a cidade e imigração dos brancos para a aldeia) como fator determinante da aquisição e da competência lingüística: "a língua acaba para os que vão morar fora da área, sem contato com a civilização própria"; "não deixar entrar branco na área"; "porque aqui na cidade só nós fala, eu estando fora da área, não posso aprender mais".

A meta do bilingüismo equilibrado: argumentos principais

$\mathrm{Na}$ análise dos argumentos utilizados nos enunciados das respostas sobre preferência lingüística, verificamos, para aqueles que moldaram suas qualificações simetricamente pelo pró-bilingüismo, a utilização preferencial dos seguintes argumentos, denominados, doravante, pela tipologia abaixo:

Preferência lingüística Argumentos mais usados (respostas)Próbilingüismo: LP + Llajgdfh

A favor do bilingüismo estão argumentos baseados na maior capacidade comunicativa dentro e fora do grupo (a); maior capacidade de defesa frente a destinatários não-índios (b); identidade étnica (d), definida como valor de diferenciação nacional, e ao mesmo tempo de identificação com este nacional do qual se percebe parte: "nós que vivemos num país chamado Brasil". Está presente também a idéia de maior "desenvolvimento" e "envolvimento" na sociedade (f), entendidos como participação na economia de mercado, através de cooperativas ou cantinas indígenas - uma nova atividade econômica pós-contato, conquistada pela grande maioria dos grupos indígenas acreanos após a fase de "cativeiro" entre patrões seringalistas e "barracões".

Ainda: a argumentação preferencial utilizada para justificar a escolha 
pelo bilingüismo revela uma concepção sobre o lingüístico que em primeiro lugar realça-lhe a funcionalidade comunicativa (a) e reforça sua função informativa (g), além de se utilizar do recurso da lingua(gem) para nada explicar ou para negar qualquer reflexão, através do processo de silenciamento, dúvida, generalizações e totalizações resumíveis no argumento (j).

Assim, se por um lado, as respostas pró-bilingüismo revelam-nos as expectativas e perspectivas indígenas de extensão e intensificação das práticas de interação social via linguagem, com mais comunicação (a) e mais informação $(\mathrm{g})$, revelam também o aspecto "mítico" ou de "bloqueio da reflexão metalingüístico" pela cristalização dos enunciados tipo (j). Essa tendência revelada na análise, em nosso caso, coincide com o que Munoz e Hamel, na sociolingüística que desenvolvem no México, descrevem e analisam, em seus trabalhos sobre a consciência metalingüística dos Otomi, como a ideologia da "desproblematização", pela congruência e a simetria da representação sobre o bilingüismo.

Representa-se, assim, na consciência desses falantes, um bilingüismo possível no plano das expectativas e do imaginário, próprios à utopia indigenista e indígena atual, no qual se daria a convivência simétrica e igualitária das duas (ou mais) línguas, na vontade de um país multiétnico, paraíso terrestre vislumbrado nessa mitologia.

No eixo simétrico das argumentações, as respostas pró-bilingüismo fizeram uso de toda a tipologia, reunindo em um mesmo enunciado argumentos tanto exclusivos de LP como os exclusivos de LI, tentando obter a "congruência" pela reunião de elementos contraditórios e assimétricos como: (a) e (b), (d) e (f) etc.

Assim, os falantes reuniram nesse eixo todo o repertório paradigmático das concepções sobre o lingüístico e o conflito, argumentando sobre suas escolhas a partir da "teoria da congruência" e da "desproblematização do conflito", numa lógica de qualificações simétricas a respeito das tendências historicamente contrastantes. Através desta, põe-se em relação nãoconflituada aspectos contraditórios ou dissonantes na representação da diglossia. Assim, elementos afetivos como reconhecidamente da língua 
indígena como marca de etnicidade, e elementos da práxis comunicativa, como a maior necessidade funcional da língua dominante, o português, coexistem na consciência indígena, resultando numa visão congruente do deslocamento histórico da língua indígena e da tendência, já bastante comprovada nesta análise (e em outras), de substituição das línguas maternas indígenas pelo português.

\section{Referências bibliográficas}

AMADIO, Massimo et ai. Educación y pueblos indígenas en Centro America - un balance crítico. Santiago: UNESCO/OREALC. 1987.

BENTOLELA, A., GANI, L. Langues et problèmes d'éducation en Haiti. Langage, Paris, n.61, p.117-127, 1981.

BOURDIEU. P. L'économie des échanges linguistiques. Langue Française, Paris, n.34, p. 17-34, 1977.

BOUTET, J. Phrases ou discours à l'écoleprimaire: sociolinguistique et école; Théories et pratiques de la sociolinguistique. Paris, Les presses Universitaires de France VIII, 1980. p.553-568 Groupe de recherche pratique de la langue maternelle.

CUMMINS, Jim, SWAIN, M. Bihngualism in Education. London: Langman, 1986.

CUMMINS, Jim, SWAIN, M. Empowering Minority Students: a framework of intervention. Harvard Educational Review 56(1), p. 18-36, 1986.

COHEN, Marcel et ai. L'Écriture et Ia psychologie des peuples. Paris, Librairie Armand Colin, 1963. 
DERRIDA, Jacques. Gramatologia. Tradução por Miriam Schneidermann, Renato J. Ribeiro - Série Filosofia Estudos, [s.1.]: Ed. Perspectiva, 1973.

GARMADI, Y. La sociolinguistique. Paris: Presses Universitaires de France, 1981.

GLEITMAN, Lila, WANNER, Eric. Language acquisition: The state of art. Cambridge: Cambridge University Press, p.3-50: Language acquisition: The state of the state of art. 1982.

GOW, Pet. Could Sangama read: grafic sistems and writing between the Piro in Peru. In: Anais do $46^{\circ}$ Congresso de Americanistas. Amsterdam, 1988.

GOODY, Jack. La raison graphique - la domestication de la pensée sauvage. Paris: Editions Minuit, 1979.

GOODY, Jack. Literacy in traditional societies. Cambridge, 1968.

GOURHAN, Leroy. Le geste et la parole. Technique et langage. Paris, [s.d.], p.262-300.

HAMEL, Rainer Enrique, SIERRA, M. Tereza. Diglosia y conflicto intercultural..Bo/eí/z/z de antropologia americana, [s.l.]: n.8, p.89110, 1983.

HAMEL, Rainer Enrique, MUNOZ, Hector. Le conflit linguistique dans Ia Vallée de Mesquital Mexique. Langage etsocieté. [s.1.]: n.23, p.333, 1983.

HAMEL, Rainer Enrique, MUNOZ, Hector. El contexto sociolinguístico de la ensehanza y adquisición del Espanol en escuelas indígenas 
bilingües en Valle de Mesquital. Estudos de Linguística Aplicada. México, n. especial, 1983.

HAMEL, Rainer Enrique, MUNOZ, Hector. Conflit socioculturel et education bilingüe: les cas des indiens Otomi au Mexique. Interaction par leLangage. [s.l.]: UNESCO: v.26, 1984.

HAMEL, Rainer Enrique, MUNOZ, Hector. El conflicto lingüístico en una situación de diglosia. Funciones sociales y consciência dei lenguaje. México: p. 13-35, 1987.

HAMEL, Rainer Enrique, MUNOZ, Hector. Determinantes sociolinguísticas de Ia educación indígena bilingüe. In: Signos. México: Universidad Autônoma Metropolitana Iztapalapa, 1988.

HEIMBECHER, C. The indian education dilemma - Sheshatshit Innu beliefs about schooling their youth. Community Concepts, Criticism and suggestions. Toronto: Thesis in OISE, 1988.

HELLER, Mônica. Bonjour, hello? negociations de choix de langue à Montreal. In: Le Français: études sociolinguistiques. Montreal: Linguistic Research, p. 121-130, 1979.

HEREDIA, Christine de. Intercompréhension et malentendus - Étude d'intéraction entre étrangers et autochtones. Paris: Université Paris, 1986. n.71, p.48-69: Langue Française.

HOWAH, A.P.R. Natural methods of language teachingfrom Montaigne to Berlitz. A History of English language teaching. Oxford: Oxford University Press, 1984. cap.14, p. 192-208.

KRISTEVA, Julia. História da linguagem. Tradução por Maria Margarida Barahona. 70.ed. [s.1.]: Coleção Signos, 1969. 
LACOSTE, M. La vieille dame et le médecin: contribuition à 1'analyse des échanges linguistiques inégaux. Études de Linguistique Aplique. [s.1.]:n.37, p.34-43, 1980.

LAFONT, Robert. A propôs de 1'enquête sur Ia diglossie: 1'intercesseur de Ia norme. Lengas. Montpellier, 1977. n.1, p.31-39.

LAFONT, Robert. Stéréotypes dans 1'enquête sociolinguistique. Lengas. Montpellier, 1980. n,7, p.79-85.

MONTE, Nietta. Alfabetização e pós-alfabetização indígena - Uma experiência de autoria. Em aberto: Educação indígena, Brasília: INEP/MEC, n.21, 1984.

MONTE, Nietta. Análise de uma experiência de autoria. Revista Brasileira deEstudos Pedagógicos, Brasília: INEP/MEC, n.157, 1986.

MONTE, Nietta. Ler e escrever - Uma experiência de autoria dos índios do Acre. In: Revista Centro de Estudos Vera Cruz, São Paulo, n.4, 1988.

MONTE, Nietta. Por uma educação indígena diferenciada. Brasília: MinC, 1987. p.11-15: Escolas formais: agências mediadoras.

MONTE, Nietta. Por uma educação indígena diferenciada. Brasília: MinC, 1987. p.65-75: Situação atual das escolas indígenas.

MONTE, Nietta. Pueblos índios, Estados y educación. Lima, 1989. p.211-223: Algunas concepciones indígenas de educación.

MONTE, Nietta. índios do Acre - Relatório do 2>-Encontro de Educação Indígena da OPAN. In: A Conquista da escrita. São Paulo: Ed. Iluminuras, 1989. p.128-136. 
MUNOZ, Hector Cruz. Testimonios metalinguísticos de un conflicto intercultural: reivindicación o solo representación de Ia cultura Otomi? In: Funciones sociales y consciência dei lenguaje. México, 1987.

MUNOZ, Hector Cruz. Una experiência de alfabetización bilingüe en comunidades mazahuas dei Estado de México. Informe general 198788. México, 1989.

OLSON, David, TORRANCE, Nancy, HILDYARD, Angela. Literacy, language and learning. Cambridge: Cambridge University Press, 1986: The nature and consequences of reading and writing.

ONG, Walter Y. Orality and literacy. Oxford: Oxford University Press, 1982.

PIAGET, Jean, CHOMSKY, Noam. Language learning: the debate between Jean Piaget and Noam Chomsky. Cambridge: Harvard University Press, 1980. p.23-54: Opening the debate. The psychogenesis of knowledge and its epistemological significance. On cognitive structures and their development: a reply to Piaget.

SCRIBNER, COLE. Literacy without schooling. Oxford: Oxford University Press, 1978.

SIERRA, M. Tereza. Identidad étnica en Ias prácticas discursivas. México: Universidade Veracruzeana, 1987. p.73-85: Funciones sociales y consciência dei lenguaje.

STERN, H.H. Fundamental Concepts of language teaching. Oxford: Oxford University Press, 1983. p.452-476: cap.20, Language teaching theories as theories of teaching methods. 
WELLS, Gordon. Language, literacy and education. Cambridge: Cambridge University Press, 1987. learning through interaction.

YALDEN, Y. Principies of course design for language teaching. Cambridge: Cambridge University Press, 1987. p. 13-48: parte 2, Language teaching and linguistics: current issues.

ZUNIGA, Madalena et ai. Educación enpoblaciones indígenas. Politicas y estratégias en America Latina. Santiago: UNESCO/OREALC, 1987.

Recebido em 27 de junho de 1991

Nietta Lindenberg Monte é mestranda em Educação na Universidade Federal Fluminense (UFF), pesquisadora da Faculdade Latino-Americana de Ciências Sociais (FLACSO) e presidente da Comissão Pró-índio do Acre.

A research on bilingualism has been conducted involving indians as teachers, their students and relatives. This article portraits some sociolinguistic variables related to the teaching and usages of Portuguese and indians' languages, surpassing the attitudes and linguistic awareness of the people concerned. Facts reveal a conflictant and disadvantageous coexistence coexistence between Portuguese and indians' languages. The historical trends point out to a progressive expansion ofPortuguese among indians and the fading out of the native languages. Since ali projects related to indians survival socialization in this continent are commited with balanced bilingual experiences, special bilingual curricula are urgently recommended, in Search for a harmonious bilingualism stillfarfrom our reach. 
Cet article fait Vanalyse de quelques variables socio-linguistiques concernantVemploi et l'enseignementdes langues indigènes etportugaise, au-delà de l'attitude et de Ia conscience linguistique des maitres indigènes qui les apprennent et de leurs eleves et parents qui sont dans le projet d'education coordonnépar Vequipe de cette recherche. Le contactsocial d'un bilinguisme equilibre est le but de Ia plupart des projets lies à l'avenir des indigènes. Pour ça, on renforce toujours Ia necessite d'élaboration des programmes bilingües pour les écoles indigènes brésiliennes, suivant Vexemple d'autrespaysdu continent. Ce besoin se pose en regime d'urgence parce que nous sommes bien lointains d'un bilinguisme harmonieux; au contraire nous assistons à une co-existence $d$ 'antagonisme des langues indigènes avec Ia langue nationale, avec des forts signes historiques d'expansion progressive du portugais et rétraction ou rétraction et disparition des langues indigènes.

Analiza algunas variables sociolingüísticas relativas a Ia utilización yala ensenanza de lenguas indígenasy portuguesa, además de Ia actitud y de Ia consciência lingüística de los índiosprofesores, que Ias enseiian, y de sus alumnos y parientes involucrados en elproyecto de educación, coordinado por ei equipo de esta investigación. La vivência social de un bilingüismo equilibrado ha sido Ia meta de Ia mayoría de losproyectos ligados ai futuro de los indios. Para tal efecto se ha enfatizado Ia necesidad de elaborar currículos bilingües para Ias escuelas indígenas brasileiras, a ejemplo de Io que ocurre en otrospaíses dei continente. Esa necesidad se coloca en régimen de urgência, en vista que estamos lejos de un bilingüismo armónico; ai contrario, hemos asistido a Ia coexistência conflictiva y asimétrica de Ias lenguas indígenas con Ia lengua nacional, confuertes indícios históricos de progresiva expansion de português e impedir ei desaparecimiento de Ias lenguas indígenas. 